\title{
THE INFLUENCE OF PERCEIVED SOCIAL SUPPORT AND SELF- EFFICACY ON RESILIENCE AMONG FIRST YEAR MALAYSIAN STUDENTS
}

\author{
Shreas Suresh Narayanan* and Alexius Cheang Weng Onn \\ Division of Psychology (\& Behavioural Sciences), International Medical \\ University, Kuala Lumpur, MALAYSIA \\ "Corresponding author: shreas.sn@gmail.com
}

To cite this article: Shreas Suresh Narayanan and Alexius Cheang Weng Onn. 2016. The influence of perceived social support and self-efficacy on resilience among first year Malaysian students. Kajian Malaysia 34(2): 1-23. http://dx.doi.org/10.21315/km2016.34.2.1

To link to this article: http://dx.doi.org/10.21315/km2016.34.2.1

\begin{abstract}
This study sought to determine whether perceived social support and self-efficacy were significant predictors of resilience among students when the effects of other variables such as stress, age, gender, and cumulative grade point average (CGPA) were controlled for. The effect of the interaction between perceived social support and self-efficacy on resilience was also tested. The study sample consisted of 377 first year local undergraduate students from a public university in Malaysia. Multiple regression was used to analyse the data. The results indicated that both perceived social support and self-efficacy were significant predictors of resilience as higher scores on perceived social support and on selfefficacy scales predicted higher resilience. The interaction effect between these variables was also positive and significant. Further analysis using ordered probit model revealed that when a student scored higher on levels of perceived social support as well as on self-efficacy, it lowered the probability of the student being in the low resilience category and increased the probability of being in the moderately resilient and highly resilient categories. The interaction effect remained significant across all categories of resilience.
\end{abstract}

Keywords: ordered probit, perceived social support, resilience, self-efficacy, university students

\section{INTRODUCTION}

A large volume of research has centred on the concept of resilience in order to understand the process of how individuals learn to cope with hardship and 
become stronger (Cicchetti, 2010; Sun and Stewart, 2007; Werner and Smith, 1992). However, much of the literature has focussed mainly on how to cultivate resilience among children and adolescents living in adverse conditions-for example, poverty or having mentally ill parents (e.g. Benard, 1993; Brooks, 2006; Werner and Smith, 1992). Though some authors have defined resilience as the ability to recover from an adverse event (Cicchetti, 2010; Wright and Masten, 2005), the present study incorporates the ideas of Pooley and Cohen (2010) and Wagnild (2009) to extend the definition of resilience as the ability of an individual to recover from an adverse event by drawing upon internal and external sources of support.

According to Masten and Garmezy (1985), resilience encompasses three concentric aspects in a youth's life which consists of an individual's attributes, support from family and external sources of support. They argue that to be considered resilient, one must encounter hardship because resilience springs from adversity. Other authors have broadened the concept of resilience to include risk and protective factors. The former encompasses all factors that result in a negative outcome, while the latter includes all factors that buffer the negative effects (Ortega, Beauchemin and Kaniskan, 2008; Prelow and Loukas, 2003). An individual who is experiencing great stress will require more protective factors to ensure that his or her development is not impaired (Werner and Smith, 1989).

The present study looks at resilience among Malaysian young adults undergoing a transition phase in their lives. More specifically, it looks at the resilience of students entering university for the first time. First year students joining a university, usually situated away from home, have to cope with the challenge of leaving a familiar environment and adjusting to a new environment (Habibah, Nooreen and Rahil, 2010). They also have to face the challenge of adjusting to adulthood (Tasleem, Strydom and Strydom, 2013). Thus, external and internal protective factors such as a good support system and self-efficacy may help them to cope better with these twin challenges (Enochs and Roland, 2006; Tasleem, Strydom and Strydom, 2013).

Rozumah and Nor Sheereen (2009) as well as Tam and Yusooff (2009) have postulated that since Malaysians are ingrained with values and traditions that place importance on family ties, family support is a critical factor in developing resilience. On the other hand, it has also been suggested that as individuals enter the adolescent period, they begin to feel more comfortable disclosing personal matters to their friends or a significant other rather than family (Rozumah and Nor Sheereen, 2009). In the literature, family, friends and "significant other" are part of what has been identified as perceived social support (Zimet et al., 1988). Other factors have also been assumed to influence resilience; Rahil et al. (2006), for example, believed that greater self-efficacy leads to higher perseverance and greater resilience among students. However, to our knowledge, there has been no published study on the effects of both self-efficacy and social support on the resilience of university students. 


\section{SOCIAL SUPPORT AND RESILIENCE}

Perceived social support was defined by Shumaker and Brownell (1984) as an exchange of resources between at least two individuals where not less than one individual perceives that the exchange enhances his or her well-being. Perceived social support makes a person more resilient in times of stress and prevents a psychopathology from developing (Ozbay et al., 2007). It also equips an individual with the necessary resources to cope with a crisis (Chi et al., 2011).

An individual may perceive to receive support from family, friends or a significant other. Studies examining the different types of social support in different contexts have yielded interesting outcomes. Mattanah et al. (2010) show that perceived social support, in general, allows an individual to cope with hardship and bounce back from adversity. Zaleski, Levey-Thors and Schiaffino (1998) reported that perceived social support from friends can ease adjustment issues faced by students in college or university. Frey and Rothlisberger (1996), who examined social support among adolescents, found that they confided in friends more frequently on minor issues but turned to family on issues that caused them major distress. Interestingly, Prezza and Giuseppina (2002) show that perceived social support from friends and "significant other" decreases with age. However, all of the aforementioned studies relate to resilience only indirectly as this variable was not the main variable under study.

Studies in Malaysia that included social support and resilience treated both as independent variables (e.g. Saim, 2013; Achour and Mohd Roslan, 2014). In contrast, one of the objectives of the present study is to determine whether perceived social support predicts resilience.

\section{SELF-EFFICACY AND RESILIENCE}

Self-efficacy is another key variable in determining resilience (Warner and Smith, 1982). It is an innate characteristic found in every individual that can be developed to act as a buffer against negative circumstances. Bandura (1997) defined self-efficacy as an individual's personal judgement of his or her capabilities in successfully carrying out a task. Necessary emotional resources such as self-efficacious beliefs are essential for effective coping and the development of resilience. When individuals with high self-efficacy are faced with adversity, they are more able to control their thoughts and persevere through hardship as compared to individuals with lower self-efficacy. Also, high selfefficacy in an individual is known to be a major predictor of successfully completing school (Hamill, 2003). In their seminal work to determine whether perceived coping and cognitive control self-efficacy govern negative thoughts pertaining to sexual assailants, Ozer and Bandura (1990) found that when women perceived that they had control over a situation, they were better able to defend 
themselves against the sexual assailant. Their findings underscore the importance of self-efficacy in helping an individual to persevere when faced with adversity, although the direct relationship between this variable and resilience was not examined.

In a different context, Kukic (2008) found that perceived self-efficacy was a predictor of academic achievement and of how well a person adapts and copes with college life. So far, there have been a lack of studies linking selfefficacy to resilience in the Malaysian context. One study, however, looked at self-efficacy and resilience among international students in Malaysia (Sabouripour and Roslan, 2015). Elsewhere, as with perceived social support, studies related to self-efficacy and resilience did not look at the predictive ability of self-efficacy on resilience (e.g. Garza, Bain and Kupczynski, 2014; Speight, 2009). The present study aims to test exactly that.

\section{RECIPROCITY BETWEEN PERCEIVED SOCIAL SUPPORT AND SELF-EFFICACY}

Green and Rodgers (2002) examined the reciprocal relationship between mastery and perceived social support among single mothers found that having higher mastery led to a better ability in perceiving and seeking support from others when needed. Similarly, higher levels of perceived social support resulted in better mastery on carrying out tasks. A similar study conducted by Luszczynska, Nihal and Schwarzer (2005) that aimed at determining whether self-efficacy and perceived social support were predictors of finding benefits in cancer, found that patients who utilised both personal and social resources had a more optimistic outlook. These findings show that there is a link between both perceived social support and self-efficacy which may interact to predict resilience. The present study determined if indeed an interaction between the two variables existed to predict resilience.

\section{OTHER VARIABLES AND THEIR RELATIONSHIP TO RESILIENCE}

Various studies have found that variables such as age, gender, race, students' cumulative grade point average (CGPA) and stress influence resilience (Gooding et al., 2011; Feinstein and Hammond, 2004; Urquhart and Pooley, 2007; Li, 2008; Sanders and Sanders, 2009; Wasonga, Christman and Kilmer, 2003; Wilks and Croom, 2008; Clifton et al., 2004). The effects of these variables were therefore held constant in the present study to ensure that their effects do not affect the main variables. 


\section{THE PRESENT STUDY}

The present study was conceived within the broader framework of the theory of resilience which has been discussed widely (Petersen, 1988; Hines, Merdinger and Wyatt, 2005). The conceptual framework for the study was guided by this theory.

The theory of resilience posits that when an individual makes the transition from adolescence to emerging adulthood, the level of autonomy increases and more often than not, support is sought from friends and peers, rather than from family (Petersen, 1988). In addition, young adults develop the capacity to draw upon their internal resources of resilience such as self-efficacy and self-confidence in order to deal with the challenges that they may encounter (Hines, Merdinger and Wyatt, 2005). This study, therefore, sought to determine whether perceived social support and self-efficacy were predictors of resilience among first-year university students, after controlling for variables such as age, gender, race, stress level and CGPA. This is an interesting group because it faces the twin challenges of adapting to a new environment and adjusting to adulthood. Although there have been previous studies on resilience among first year college students, these studies have had different purposes and aims. Calmes (2012), for example, examined the role of resilience in the relationship between facing adversity as a child and the subsequent dependence on substances in adulthood. It was found that resilience was not a predictor of substance abuse in later life. In another study, Morgan (2016) sought to determine factors of resilience among art and design students. She found that factors such as financial stability, peer support and a relatively stress free environment predicted academic success. The conceptual framework guiding the study is shown in Figure 1.

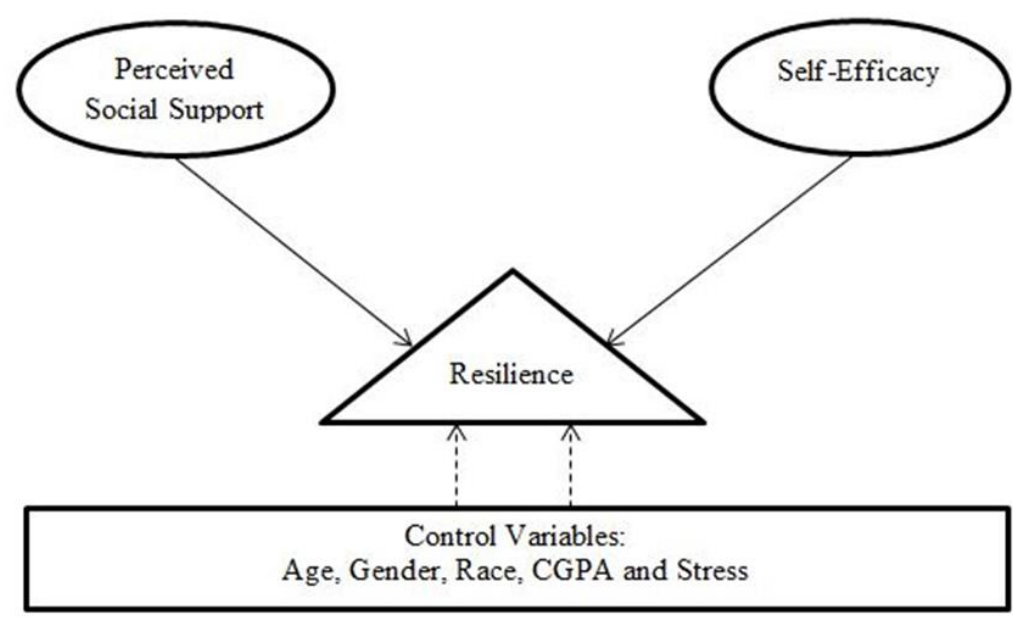

Figure 1: The conceptual framework. 
The connection between perceived social support and resilience has long been recognised, but not much has been done in terms of conceptualising it in relation to resilience (Armstrong, Bernie-Leftkovich and Ungar, 2005). A similar view was echoed by a later study (Li, Ji and Chen, 2014) that argued though perceived social support was a well-known protective factor that promoted wellbeing, few studies have examined the role of different types of perceived social support, let alone link it with resilience. In this study, different types of perceived social support (from family, friends and significant other) are posited to predict resilience positively, as indicated by the unidirectional bold line linking "social support" to "resilience". Students who have better perceived social support are hypothesised to have significantly higher resilience.

Sagone and Caroli (2013) studied the relationship between resilience, self-efficacy, and thinking styles among 130 Italian adolescents. It was found that with regard to resilience, adolescents who had high resilience perceived themselves to be highly effective in general and scholastic tasks. Another study by Cassidy (2015) sought to determine the relationship between academic selfefficacy and academic resilience among 435 British undergraduate students. It was found that these variables were positively correlated. Although these studies looked at self-efficacy and resilience, the first study tested the predictive ability of resilience in determining self-efficacy while the second study examined academic self-efficacy and resilience, respectively. In the present study, we posit that self-efficacy predicts resilience positively, as shown by the unidirectional bold line linking "self-efficacy" to "resilience" in the Figure 1. Students who have higher self-efficacy are, therefore, hypothesised to have significantly higher resilience.

Studies have noted the reciprocal relationship between perceived social support and self-efficacy (e.g. Green and Rodgers, 2002; Luszczynska, Nihal and Schwarzer, 2005). In addition, Karademas (2006) pointed out that having a strong sense of self-efficacy and perceived social support increases an individual's optimism which results in positive health outcomes, hence prompting us to examine the possible interaction between these two variables on resilience. This is shown by the bidirectional arrow between the two, in Figure 1.

To isolate the effects of perceived social support and self-efficacy on resilience, variables such as age, gender, race, CGPA and stress that may confound the main relationships are controlled for. This is shown by the box below resilience with dotted lines pointing upwards toward resilience. 


\section{METHOD}

\section{Participants}

The study population consisted of 377 local, first-year students in introductory level courses in the Social Sciences, at a public university.

Students in introductory courses are an appropriate population to sample from because they attract students majoring in various fields from across the university. Individuals from diverse fields of academic study were therefore well represented in this population. Of the nine introductory courses that were available, a random number generator was used to determine the course from which the sample was to be drawn. Introductory Psychology was the course selected.

A public university was chosen because it better reflected the diverse socio-economic and demographic backgrounds that students come from.

The sample consisted of 76 (20.2\%) males and 301 (79.8\%) females. Of this, there were 272 Malays (72.2\%), 87 Chinese (23.1\%), 18 Indians and others $(4.8 \%)$. The mean age of participants was 22 years. The sample was broadly reflective of Malaysia's multi-ethnic population (Malays, Chinese, Indians and others, with Malays forming the majority). The preponderance of females in institutions of higher learning, in general (UNICEF, 2005; Latifah, 2015) was also reflected in the sample.

The study was approved by the ethics committee of the International Medical University and permission to conduct this study in the public university was obtained. A pilot study consisting of 50 students was undertaken to identify whether the questionnaire was easily understood. No ambiguities were detected. Due to the policy of the public university, no incentives were given to participants.

\section{Materials}

Four questionnaires were used to measure resilience, perceived social-support, self-efficacy, and stress levels among students, respectively. Demographic variables such as age, gender, race and CGPA were also included. All questionnaires were bilingual, in English and Malay.

\section{Resilience}

Resilience among students, the dependant variable, was measured using the Resilience Scale developed by Wagnild and Young (1993). It consists of 14 items designed to determine individual resilience at the point of study, and has a 7point rating scale ranging from 1 (Strongly disagree) to 7 (Strongly agree). The Resilience Scale has a Cronbach's Alpha coefficient of 0.93 indicating a high 
internal consistency (Wagnild, 2009). The Malay version was also kindly provided by Dr. Gail Wagnild. The bilingual version had a Cronbach's Alpha of 0.86 .

\section{Perceived Social Support}

Perceived social support, one of the two independent variables, was measured using the Multidimensional Scale of Perceived Social Support (MSPSS) developed by Zimet et al. (1988). It consists of 12 items that assess three different sources of support which included support from family, friends and "significant other". It has a 7-point Likert scale ranging from 1 (Very strongly disagree) to 7 (Very strongly agree) and a Cronbach's Alpha coefficient range of 0.85-0.91. A Malay version that had been validated by $\mathrm{Ng}$ et al. (2010), with a Cronbach's Alpha coefficient of 0.89 , was used. The reliability test for the present study showed that the bilingual version had a Cronbach's Alpha of 0.91 .

\section{Self-Efficacy}

This was measured using the General Self-Efficacy Scale developed by Schwarzer and Jerusalem (1995). It consists of 10 items that assesses how an individual reacts to new or challenging tasks in various aspects of life. It has a 4point Likert Scale ranging from 1 (Not at all true) to 4 (Exactly true) and a Cronbach's Alpha coefficient range of 0.76-0.90. The Malay version was obtained through back translation and the reliability coefficient obtained from the pilot study was 0.82 . The final bilingual version had a reliability coefficient of 0.84 .

\section{Perceived Stress}

Since stress is known to affect resilience, its effects were controlled for by determining students' perceived stress over the past one month using the Perceived Stress Scale developed by Cohen, Kamarck and Mermelstein (1983). It consists of 10 items measuring stress perceived by a student with a 5-point Likert Scale ranging from 0 (Never) to 5 (Very Often). It has a Cronbach's Alpha of 0.79 . The Malay version, validated by Al-Dubai et al. (2012), was used in the present study and had a reliability coefficient of 0.82 . In the present study, the bilingual version used had a Cronbach's Alpha value of 0.73 .

Permission to use the various scales and their Malay versions were obtained from the respective researchers and is gratefully acknowledged. 


\section{Procedure}

The final version of the questionnaire was distributed to 438 students who gave their signed consent to participate in the study. Participation was voluntary and subjects were told that they could withdraw at any stage. It took approximately 20 minutes to complete the questionnaire. With 377 useable responses returned, the response rate was $86 \%$.

\section{Data Analysis}

Data were analysed using PASW Version 18 and STATA Version 12. Preliminary analysis was done by obtaining descriptive statistics and correlations for all variables. The assumptions of multiple regression were also checked for. The presence of multicollinearity was tested by computing the Variance Inflation Factor (VIF) and Tolerance values. The rule of thumb is that multicollinearity poses a problem when VIF values exceed 10 and Tolerance values approach 0 (Gujarati, 2003; Tabachnick and Fidell, 2007). In this study, the VIF value was below 1.2 and Tolerance values were above 0.8 for all of the independent variables except race, which was then dropped from the regression analysis.

The interaction variable was the product of perceived social support and self-efficacy which caused it to be highly collinear with the main independent variables. To reduce multicollinearity and provide a more meaningful interpretation of the intercept term, mean centring was done. The sample mean of each continuous independent variable was subtracted from each corresponding score before being squared (Tabachnick and Fidell, 2007; Warner, 2012). This also allows the effects of each independent variable to be distinguished from the interaction variable (Warner, 2012).

Mean centring changes the interpretation of the results; instead of the yintercept representing the resilience score when each independent variable is equal to 0 , it will now represent the resilience score of a student who has mean values for the perceived social support and self-efficacy scales (Warner, 2012).

A standard multiple regression equation was estimated to determine the relationship between the independent variables and the dependent variable. Further analysis using ordered probit was done to gain additional insights regarding the predictor variables under study. As the prerequisite for using the ordered probit model was that the dependent variable must be in an ordered categorical form, resilience was reclassified into three categories (low, moderate and high) by regrouping students' resilience scores following the ranges specified in Wagnild (2009). 


\section{RESULTS}

The regression analyses found that social support and self-efficacy were significant predictors of resilience, after controlling for other factors such as stress, age, gender and CGPA of participants (Table 1).

Table 1: Multiple regression of self-efficacy and perceived social support as predictors of resilience among a sample of 377 first-year students at a public university

\begin{tabular}{lccccc}
\hline Variables & $b$ & $S E$ & $\beta$ & $t$ & $p$ \\
\hline Age & 0.16 & 0.20 & 0.03 & 0.76 & 0.45 \\
Gender & -0.18 & 0.87 & -0.01 & -0.24 & 0.84 \\
CGPA & -0.26 & 0.71 & -0.02 & -0.37 & 0.71 \\
Stress level & -0.25 & 0.07 & -0.14 & -3.31 & 0.00 \\
Perceived social & 0.09 & 0.04 & 0.11 & 2.42 & 0.02 \\
support & & & & & \\
Self-efficacy & 1.16 & 0.10 & 0.53 & 12.34 & 0.00 \\
\hline
\end{tabular}

Note: $\mathrm{R}^{2}=0.397$; Adjusted $\mathrm{R}^{2}=0.388 ; \mathrm{df}=376$.

The total variance explained by the model was $39.7 \%\left(R^{2}=0.397, \mathrm{~F}(6\right.$, $370), p<.05)$. The results support the first two hypotheses; perceived social support significantly predicted resilience $(\beta=0.11, p<.05)$, as did self-efficacy $(\beta=0.53, p<.05)$. The standardised beta $(\beta)$ coefficients indicate that selfefficacy had a larger positive impact on resilience relative to perceived social support when the control factors were held constant.

Controlling for stress, CGPA, age and gender, the results suggest that a one point increase in the perceived social support scale results, on average, in an increase of 0.09 points in the resilience score. Similarly, a one point increase in the self-efficacy scale increases the resilience score by 1.16 , as indicated by the unstandardised beta value $(b)$.

Stress was the only significant factor among the control variables. As anticipated, stress lowered resilience when all other factors were held constant $(\beta=-0.14, p<.05)$; a one point increase in the stress scale reduces the score on resilience by 0.25 .

Since perceived social support significantly predicted resilience, another regression was run to determine which form of social support had the highest ability to predict resilience. The results are shown in Table 2. 
Table 2: Multiple regression for the subscales of perceived social support and their corresponding predictive ability of resilience

\begin{tabular}{lccccc}
\hline Variables & $b$ & $S E$ & $\beta$ & $t$ & $p$ \\
\hline "Significant Other" & -0.03 & 0.11 & -0.14 & -0.23 & 0.82 \\
Family & 0.34 & 0.13 & 0.16 & 2.56 & 0.01 \\
Friends & 0.45 & 0.13 & 0.21 & 3.51 & 0.00 \\
\hline
\end{tabular}

Note: $\mathrm{R}^{2}=0.095 ;$ Adjusted $\mathrm{R}^{2}=0.087 ; \mathrm{df}=376$.

Perceived social support from friends and family were significant predictors of resilience while "significant other" was not. However, support from friends was a slightly better predictor of resilience $(\beta=0.21, p<.05)$, relative to support from family $(\beta=0.16, p<.05)$.

To test the third hypothesis, social support was interacted with selfefficacy to see if self-efficacy remained unchanged across all levels of social support. Bearing in mind that the variables were centred, all subsequent interpretations uses the mean of each variable as the reference point. The results of the regression incorporating the interaction variable are shown in Table 3.

Table 3: Multiple regression of perceived social support and self-efficacy as predictors of resilience when both are centred and interacted, among a sample of 377 first-year students at a public university

\begin{tabular}{lccccc}
\hline Variables & $b$ & $S E$ & $\beta$ & $t$ & $p$ \\
\hline Age & 0.18 & 0.20 & 0.04 & 0.89 & 0.38 \\
Gender & -0.39 & 0.86 & -0.02 & -0.46 & 0.65 \\
CGPA & -0.24 & 0.70 & 0.01 & -0.34 & 0.73 \\
Stress & -0.23 & 0.07 & 0.13 & -3.06 & 0.00 \\
Perceived social & 0.09 & 0.04 & 0.11 & 2.59 & 0.01 \\
support & & & & & \\
Self-efficacy & 1.20 & 0.09 & 0.55 & 12.82 & 0.00 \\
$\begin{array}{l}\text { Social support* self- } \\
\text { efficacy }\end{array}$ & 0.02 & 0.01 & 0.13 & 3.14 & 0.00 \\
\hline
\end{tabular}

Note: $\mathrm{R}^{2}=0.413$; Adjusted $\mathrm{R}^{2}=0.402 ; \mathrm{df}=376$. All continuous variables were centred at about the mean.

With the addition of the interaction variable, the total variance explained by the model increased slightly to $41.3 \%\left(\mathrm{R}^{2}=0.413, \mathrm{~F}(7,369), p<.05\right)$. The coefficients of self-efficacy and perceived social support remained significant.

The coefficient of the interaction term was positive and significant. Stock and Watson (2003) provide a formula for calculating the interaction effect for each variable, as follows: $b_{x_{1}}+$ (coefficient of the interaction term $\times$ score of $x_{2}$ ). For example, holding perceived social support constant at a score of 72 (upon 
84), the slope relating resilience to self-efficacy is estimated to be $1.19+(0.02 \times$ $72)=2.63$. When higher scores of social support are used, for example, scores of 75 and 78 , the value of the slope changes to 2.69 and 2.75 , respectively. This shows that the effect of self-efficacy on resilience increases at higher levels of social support.

Similarly, holding self-efficacy constant at a score of 32 (upon 40), the slope relating resilience to perceived social support will be $0.08+(0.02 \times 32)=$ 0.72 . When higher perceived social support scores of 35 and 38 are substituted into the equation, the value of the slope increases to 0.78 and 0.84 , respectively. Again, this suggests that the effect of perceived social support on resilience increases at higher levels of self-efficacy.

A more advanced analysis using ordered probit was done to determine how well the independent variables predicted the categories of resilience. Since the estimated coefficients have no direct interpretation (Greene, 2004), the marginal effects are shown in Table 4. They indicate the probabilities of being in the low, moderate and high resilient groups, based on the changes in the scores of the predictor variables.

Table 4: Marginal effects of the predictor variables on the probability of being in the low, moderate and highly resilient groups based on an ordered probit model

\begin{tabular}{lccc}
\hline Variables & Low resilience & Moderate resilience & High resilience \\
\hline Perceived social support & $-0.56^{* *}$ & $0.47^{* *}$ & $0.09^{* *}$ \\
Self-efficacy & $-5.66^{* *}$ & $4.80^{* *}$ & $0.90^{* *}$ \\
Stress & $-1.49^{* *}$ & $-1.26^{* *}$ & $-0.23^{* *}$ \\
Social support* self- & $-0.09^{* *}$ & $0.08^{* *}$ & $0.01^{* *}$ \\
efficacy & & & \\
Age & -0.83 & 0.70 & 0.13 \\
Gender & 1.54 & -1.30 & -0.24 \\
CGPA & 1.85 & -1.56 & -0.29 \\
\hline
\end{tabular}

Note: ${ }^{* *}$ significant at $p<.05$. Marginal effects are reported in percentages. All continuous variables have been centred at about the mean.

The marginal effects of social support, self-efficacy, stress and the interaction terms remained significant in influencing the probability of being in one of the three categories of resilience.

The results suggest that a unit increase in the social support score decreased the probability of being in the low resilience category by $0.6 \%$ and raised the probability of being moderately and highly resilient by about $0.5 \%$ and $0.09 \%$, respectively. Likewise, a unit increase in the self-efficacy score decreased the probability of being in the low resilience category by $5.7 \%$ but increased the probability of being in the moderately and highly resilient category by $4.8 \%$ and $0.9 \%$, respectively. In contrast, a unit increase in the stress score increased the 
probability of a student being in the low resilience category by $1.5 \%$ and decreased the probability of being in the moderate and highly resilient category by $1.3 \%$ and $0.2 \%$, respectively.

The interaction variable also remained significant across all three categories of resilience suggesting that the two independent variables continue to influence the outcome through interactions among themselves.

Of the two subscales of social support that were significant in the multiple regression analysis, it was found that perceiving support from family and friends decreased the probability of being in the low resilient group by $1.7 \%$ and $1.9 \%$, respectively as shown in Table 5 .

Table 5: Marginal effects for the subscales of perceived social support on the probability of being in the low, moderate or highly resilient groups based on an ordered probit model

\begin{tabular}{lccc}
\hline Variables & Low resilience & Moderate resilience & High resilience \\
\hline "Significant other" & -0.08 & 0.05 & 0.02 \\
Family & $-1.73^{* *}$ & $1.21^{* *}$ & $0.52^{* *}$ \\
Friends & $-1.89^{* *}$ & $1.32^{* *}$ & $0.57^{* *}$ \\
\hline
\end{tabular}

Note: **significant at $p<.05$. Marginal effects are reported in percentages.

Both these subscales increased the probability of being in the moderately resilient group by $1.2 \%$ and $1.3 \%$, respectively, and increased the probability of entering the highly resilient group by $0.5 \%$ and $0.6 \%$, respectively.

\section{DISCUSSION}

The results from the regressions supported all three hypotheses. The first two hypotheses suggesting that perceived social support and self-efficacy contributed to the variance in resilience, respectively, were upheld. The third hypothesis that perceived social support significantly interacted with self-efficacy to predict students' resilience was also corroborated by the data. The impact of social support on resilience was augmented by rising levels of self-efficacy; likewise, the effect of self-efficacy on resilience increased at higher levels of social support.

The significant positive relationship between perceived social support and resilience is consistent with the results of a number of previous studies (Armstrong, Bernie-Leftkovich and Ungar, 2005; Dent and Cameron, 2003; Xu and $\mathrm{Ou}, 2014)$. In an interesting study that examined marital satisfaction of Chinese under stress, an incidental finding showed that social support was a key factor in reducing the negative effects of life crises (Chi et al., 2011). Lee, Suchday and Wylie-Rosett (2012) stated that with the perception of a strong 
social support network, an individual was better able to cope with adverse situations, relative to someone who had to cope alone.

We also found that of the three sources of perceived social support, support from friends and family were significantly related to resilience while support from "significant other" was not significant. This is consistent with Masten and Reed (2002) who noted that strong bonds with family and friends were widely reported correlates of resilience.

Consistent with the prediction of the theory of resilience, our findings showed that perceived social support from friends was a stronger predictor of resilience than from the family. It appears that young adults tend to readily disclose their problems to friends rather than family members. However, this is in contrast to results reported by $\mathrm{Li}, \mathrm{Ji}$ and Chen (2014) showing that family support is essential in reducing negative emotions among the elderly, and was more important than support from friends. One possible explanation for this difference is that young adults, unlike the elderly, are more comfortable with friends and tend to perceive friends as being more capable of giving them the understanding and support they seek. Another possibility is that entering university is also a time when young adults leave their home and build new support structures through friends instead of continuing to depend on their family (Barutchu and Bert, 2013). Zaleski, Levey-Thors and Schiaffino (1998), who studied young adults, also found results consistent with ours. They postulated that young adults in college lacked emotional independence and tended to cope with the support from friends instead of family due to their similarities in demographics.

Though some studies have found that "significant other" does enhance resilience (Cohen, 2004; Rahimi and Bigdeli, 2014; Li, Ji and Chen, 2014), we found no support for this. This could be because most first-year university students tend to focus on adjusting to college life and their studies rather than engaging in a long-term commitment with a "significant other". Another possible explanation is that even for students who do have a "significant other", the nature of the relationship may vary. Some may benefit from the relationship (Cohen, 2004; Uchino, 2004) while others may experience a lot of stress from it (Umberson and Montez, 2013). This may explain why support from a "significant other" does not consistently predict resilience.

Our finding of a significant positive association between self-efficacy and resilience is in line with studies by Hung (2010) and Hamill (2003). This also validates the theory of resilience which hypothesises that students who are emerging into adulthood will adjust and solve problems by drawing upon internal resources such as self-efficacy. Having a good sense of self-efficacy helps an individual deal with adverse events effectively as they are able to control their thoughts better, which allows them to persevere through hardship (Hamill, 2003). Self-efficacious individuals more readily dismiss negative thoughts that are related to them or their capabilities as compared to those who are not selfefficacious (Ozer and Bandura, 1990). Bandura (1997) noted that individuals 
with high self-efficacy tended to have faith in their own strength and capabilities when faced with adversity.

Some studies found that the relationship between resilience and selfefficacy is bidirectional. Not only did self-efficacy significantly predict resilience, but the converse was also true. In their study to determine the relationship between resilience, self-efficacy and thinking styles among 130 Italian adolescents, Sagone and Caroli (2013) found that adolescents who were highly resilient also felt they were better able to cope with hardships in various domains in their lives. This suggests that having a good sense of self-efficacy not only predicted resilience but was also an outcome of resilience.

It is perhaps not surprising that self-efficacy emerged as a better predictor of resilience among young adults, relative to perceived social support. Individuals with a high sense of self-efficacy are better able to deal with stressors and adapt to change independently because they believe that they have control over their lives; they rely on internal forces to cope. Therefore, being able to cope from within rather than coping from the support of others is a more effective predictor of individual resilience. This is consistent with the view of Cayirdag (2012) who argues that self-efficacy is the most central concept in Lazarus and Folkman's theory of psychological stress. Lazarus and Folkman (1984) posit that the manner in which an individual views his or her capabilities determines how they handle difficulties. If they perceive hardship as being within their control, they view it as a challenge rather than a threat. This prevents them from succumbing to extreme stress (as cited in Cayirdag, 2012).

In examining the significant interaction of self-efficacy and perceived social support, we found that the impact of self-efficacy on resilience increased at higher levels of perceived social support. In other words, the slope to predict resilience from self-efficacy increased as the social support score for a student increased. Similarly, the positive impact of social support on resilience increased at higher levels of self-efficacy. This outcome is consistent with Solberg and Villarreal (1997) who found that having both self-efficacy and good perceived social support improved personal adjustment among Hispanic college students.

Among the four variables that were controlled for in our study, stress was the only variable that was significant. Not unexpectedly, stress had a negative relationship with resilience. This finding is consistent with the literature; a higher amount of perceived stress leads to a lower resilience score (Wilks and Croom, 2008). Wilks (2008) argued that a highly resilient individual perceives stressful situations as a challenge rather than a threat while an individual with low resilience had the opposite perception.

The ordered probit analyses found that both self-efficacy and social support were significantly associated with all three degrees of resilience. A higher perceived social support and self-efficacy reduced the probability of falling into the low resilience category and increased the probability of being in either the moderate or high resilience category. This finding further strengthens 
the fact that both perceived social support and self-efficacy enhances resilience (Hamill, 2003; Sagone and Caroli, 2013). Similarly, the results also imply that support from friends is a better predictor of resilience compared to support from family.

The results from the ordered probit also confirmed the findings from the multiple regression that self-efficacy was a stronger predictor of resilience. For instance, a unit increase in perceived social support scores lowered the probability of being in the low resilient category by $0.6 \%$, whereas the same increase in self-efficacy lowered the likelihood of being in the low resilient category by $5.7 \%$, which is a substantially bigger reduction. This further reinforces the point that having self-efficacious beliefs about oneself is better at predicting resilience as compared to having a good support system (Hamill, 2003; Ozer and Bandura, 1990). Interestingly, the impact of both variables in raising the probability of being in the moderately resilient category was higher when compared to their effect in increasing the probability of being in the highly resilient category. This suggests that when an individual's inherent resilience is already high, the impact of other factors like social support or self-efficacy in raising resilience any further is limited.

Stress, which was controlled for in the present study, significantly increased the probability of a student being in the low resilience category and lowered the probability of being in the moderate and high resilience category. The negative relationship between stress and resilience found in the present study has been corroborated by the findings of previous studies as well (Werner and Smith, 1992; Wilks, 2008). Clearly, stress is a risk factor that lowers resilience.

\section{LIMITATIONS AND RECOMMENDATIONS FOR FUTURE RESEARCH}

The key limitations of the study are as follows. First, since the study was conducted in a public university, the majority of participants in the sample were Malay. A sample drawn from a private university where students are predominantly Chinese, however, may yield different results. Second, a student's resilience, perceived social support, self-efficacy and stress levels were measured using self-reported responses. Therefore, biases associated with self-reporting may be present. Third, the response rate may have been higher had the policy of the university permitted the use of incentives to encourage students' participation in this study.

Future research should include a broader sample of students obtained from both public and private universities so that the results may be more representative. A larger sample of students will also make the results more generalisable. In addition, there may be many other variables that may be 
predictors of resilience which have not been examined. The framework could be broadened to include these variables.

\section{CONCLUSIONS AND IMPLICATIONS}

The key hypotheses of the theory of resilience appear to be supported by the findings of the present study. They hold some implications for intervention strategies to increase the resilience of new, incoming students; the present study found that about one third of the students in the sample had low resilience.

Since both theory and empirical findings lend credence to the idea that an individual needs good self-efficacy and self-confidence to overcome challenges, one measure is to evaluate resilience of fresh entrants and having trained counsellors to encourage those with low resilience to join activities that can help them develop their strengths. This is in line with what Linnenbrink and Pintrich (2003) advocate. They add that students engage in a task, complete it, and feel confident when they know that they can accomplish it. Additionally, workshops designed to increase self-efficacy should be organised on a regular basis. Trained facilitators should model positive behaviours such as positive thinking, setting goals and achieving them and taking charge of a situation (Margolis, 2005; Schunk, 1991).

Moreover, building social support is also critical for freshmen as they are at a transition stage and tend to turn to friends for support, as posited by the theory of resilience. Universities can assist them by encouraging students to join clubs or societies and ensuring they actively participate in them and organise events that require team work or include teambuilding exercises. Lecturers can enhance the process by assigning group academic exercises. Many universities have also implemented the mentor-mentee system where student mentees are assigned to an academic mentor. Students should be taught to be proactive and approach their mentor as an additional source of support. By equipping students with confidence and a strong network of support, resilience can be nurtured to ensure that they can deal with adversity.

\section{ACKNOWLEDGEMENTS}

This study was funded by International Medical University, Research Number: BPS I-01/2012(01)2014. 


\section{REFERENCES}

Achour, M. and Mohd Roslan Mohd Nor. 2014. The effects of social support and resilience on life satisfaction of secondary school students. Journal of Academic and Applied Studies 4(1): 12-20.

Al-Dubai, S. A., M. A. Aishangga, K. G. Rampal and Nik Aziz Sulaiman. 2012. Factor structure and reliability of the Malay version of the perceived stress scale among Malaysian medical students. Journal of Medical Sciences 19: 43-49.

Armstrong, M. I., S. Bernie-Leftkovich and M. T. Ungar. 2005. Pathways between social support, family well-being, quality of parenting, and child resilience: What we know. Journal of Child and Family Studies 14(2): 269-281. http://dx.doi.org/10.1007/s10826-005-5054-4.

Bandura, A. 1997. Self-efficacy: The exercise of control. New York: Freeman.

Barutchu, C. D. and H. Bert. 2013. The relationship between social support and quality of life in patients with heart failure. Journal of Pakistan Medical Association 63(4): 463-467.

Benard, B. 1993. Fostering resiliency in kids. Educational Leadership 51(3): 44-48.

Brooks, J. E. 2006. Strengthening resilience in children and youths: Maximizing opportunities in the schools. Children and Schools 28: 69-76. http://dx.doi.org/ 10.1093/cs/28.2.69.

Calmes, S. A. 2012. The relationship between adverse childhood events, resilience, and substance dependence among a college freshman population. $\mathrm{PhD}$ diss., The University of Toledo.

Cassidy, S. 2015. Resilience building in students: The role of academic self-efficacy. Frontiers in Psychology 6: 1781. http://dx.doi.org/10.3389/fpsyg.2015.01781.

Cayirdag, N. 2012. Perceived social support, academic self-efficacy, and demographic characteristics as predictors of perceived stress. PhD diss., Middle East Technical University.

Chi, P., S. K. M. Tsang, K. S. Chan, X. Xiang, P. S. F. Yip, Y. T. Cheung and X. Zhang. 2011. Marital satisfaction of Chinese under stress: Moderating effects of personal control and social support. Asian Journal of Social Psychology 14: 1525. http://dx.doi.org/10.1111/j.1467-839X.2010.01322.x.

Clifton, P. A., R. P. Perry, C. A. Stubbs and L. W. Roberts. 2004. Faculty environments, psychosocial dispositions, and the academic achievement of college students. Research in Higher Education 45(8): 801-827. http://dx.doi.org/10.1007/ s11162-004-5950-2.

Cicchetti, D. 2010. Resilience under conditions of extreme stress: A multilevel perspective. World Psychiatry 9: 145-154. http://dx.doi.org/10.1002/j.20515545.2010.tb00297.x.

Cohen, S. 2004. Social relationships and health. American Psychologist 59: 676-84. http://dx.doi.org/10.1037/0003-066X.59.8.676.

Cohen, S., T. Kamarck and R. Mermelstein. 1983. A global measure of perceived stress. Journal of Health and Social Behavior 24: 385-396. http://dx.doi.org/10.2307/2136404.

Dent, R. J. and R. J. S. Cameron. 2003. Developing resilience in children who are in public care: The educational psychological perspective. Routledge 19(1): 3-19. http://dx.doi.org/10.1080/0266736032000061170. 
Enochs, W. K. and K. Roland. 2006. Social adjustment of college freshmen: The importance of gender and living environment. College Student Journal 40: 6372.

Feinstein, L. and C. Hammond. 2004. The contribution of adult learning to health and social capital. Oxford Review of Education 30: 199-221. http://dx.doi.org/ 10.1080/0305498042000215520.

Frey, C. U. and C. Rothlisberger. 1996. Social support in healthy adolescents. Journal of Youth and Adolescents 25(1): 17-31. http://dx.doi.org/10.1007/BF01537378.

Garza, K., S. F. Bain and L. Kupczynski 2014. Resiliency, self-efficacy, and persistence of college seniors in higher education. Research in Higher Education Journal 26: 1-19.

Gooding, P. A., A. Hurst, J. Johnson and N. Tarrier. 2011. Psychological resilience in young and older adults. International Journal of Geriatric Psychiatry 27(3): 262-270. http://dx.doi.org/10.1002/gps.2712.

Green, B. L. and A. Rodgers. 2002. Determinants of social support among low-income mothers: A longitudinal analysis. American Journal of Community Psychology 29(3): 419-442. http://dx.doi.org/10.1023/A:1010371830131.

Greene, W. H. 2004. Econometric analysis. New Jersey: Prentice Hall.

Gujarati, N. 2003. Basic econometrics. 4th ed. New York: Mc-Graw Hill/Irwin.

Habibah Elias, Nooreen Noordin and Rahil $\mathrm{Hj}$. Mahyuddin. 2010. Achievement motivation and self-efficacy in relation to adjustment among university students. Journal of Social Sciences 6(3): 333-339. http://dx.doi.org/10.3844/jssp. 2010.333.339.

Hamill, S. 2003. Resilience and self-efficacy: The importance of efficacy beliefs and coping mechanisms in resilient adolescents. Colgate University Journal of the Science 35: 115-146.

Hines, A. M., J. Merdinger and P. Wyatt. 2005. Former foster youth attending college: Resilience and the transition into young adulthood. American Journal of Orthopsychiatry 75: 381-394. http://dx.doi.org/10.1037/0002-9432.75.3.381.

Hung, Y. Y. K. 2010. Effects of perceived self-efficacy, social support and selfadjustment to college on the health-behaviours of Chinese/Taiwanese international students. PhD diss., Kent State University College of Nursing.

Karademas, E. C. 2006. Self-efficacy, social support and well-being: The mediating role of optimism. Personality and Individual Differences 40: 1281-1290. http://dx.doi.org/10.1016/j.paid.2005.10.019.

Kukic, M. 2008. Personal and environmental characteristics as determinants of student adjustment to college. Poster presented at $38^{\text {th }}$ EABCT Annual Congress, Helsinki, Finland. 10-13 September. http://bib.irb.hr/prikazi-rad?rad=397730 (accessed 2 May 2016).

Latifah Ismail. 2015. Gender gap in higher education: Perspective on factors influencing enrolment in Malaysian universities: A university of Malaya sample. The Online Journal of Quality in Higher Education 2(4): 35-45. http://www.tojqih. net/journals/tojqih/articles/v02i04/v02i04-04.pdf

Lee, C., S. Suchday and J. Wylie-Rosett. 2012. Perceived social support, coping styles, and Chinese immigrants' cardiovascular responses to stress. Journal of Behavioural Medicine 19: 174-185. http://dx.doi.org/10.1007/s12529-011-91567. 
Li, H., Y. Ji, and T. Chen. 2014. The roles of different sources of social support on emotional well-being among Chinese elderly. PLOS ONE 9(3): 1-9. http://dx.doi.org/10.1371/journal.pone.0090051.

Li., M. H. 2008. Helping college students cope: Identifying predictors of active coping in different stressful situations. Journal of Psychiatry, Psychology and Mental Health 2(1): 1-15.

Linnenbrink, E. A. and P. R. Pintrich. 2003. The role of self-efficacy beliefs in student engagement and learning in the classroom. Reading and Writing Quarterly: Overcoming Learning Difficulties 19: 119-137. http://dx.doi.org/10.1080/ 10573560308223.

Luszczynska, A., Nihal E. Mohamed and R. Schwarzer. 2005. Self-efficacy and social support predict benefit finding 12 months after cancer surgery: The mediating role of coping strategies. Psychology, Health \& Medicine 10(4): 365-375. http://dx.doi.org/10.1080/13548500500093738.

Margolis, H. 2005. Increasing struggling learners' self-efficacy: What struggling tutors can do and say. Mentoring and Tutoring 13(2): 221-228. http://dx.doi.org/10.1080/13611260500105675.

Masten, A. and N. Garmezy. 1985. Risk, vulnerability, and protective factors in developmental psychopathology. In Advances in clinical child psychology, eds. B. Lahey and A. Kazdin,1-52. New York: Plenum Press. http://dx.doi.org/10.1007/978-1-4613-9820-2_1.

Masten, A. and M. Reed. 2002. Resilience in development. In Handbook of positive education, eds. C. R. Snyder and S. J. Lopez, 74-88. New York: Oxford University Press.

Mattanah, J. F., J. F. Ayers, B. L. Brand and L. J. Brooks. 2010. A social support intervention to ease the college transition: Exploring main effects and moderators. Journal of College Student Development 51(1): 93-108. http://dx.doi.org/10.1353/csd.0.0116.

Morgan, R. 2016. Factors of resilience that support university art and design students. PhD diss., Education Faculty, Walden University.

Ng, C. G., A. N. Amer Siddiq, S. A. Aida, N. Z. Zainal and O. H. Koh. 2010. Validation of the Malay version of the Multidimensional Scale of Perceived Social Support (MSPSS-M) among a group of medical students in Faculty of Medicine, University Malaya. Asian Journal of Psychiatry 3(1): 3-6. http://dx.doi.org/10.1016/j.ajp.2009.12.001

Ortega, S., A. Beauchemin and R. B. Kaniskan. 2008. Building resiliency in families with young children exposed to violence: The safe start initiative pilot study. Best Practise in Mental Health 4: 48-64.

Ozbay, F., D. C. Johnson, E. Dimoulas, C. A. Morgan, D. Charney and S. M. Southwick. 2007. Social support and resilience to stress: From neurobiology to clinical practice. Psychiatry 4: 35-40.

Ozer, E. M. and A. Bandura. 1990. Mechanisms governing empowerment effects: A selfefficacy analysis. Journal of Personality and Social Psychology 58: 472-486. http://dx.doi.org/10.1037/0022-3514.58.3.472.

Petersen, A. C. 1988. Adolescent development. Annual Review of Psychology 39: 583607. http://dx.doi.org/10.1146/annurev.ps.39.020188.003055. 
Pooley, J. and L. Cohen. 2010. Resilience: A definition in context. Australian Community Psychologist 22: 30-37.

Prelow, H. M. and A. Loukas. 2003. The role of resource, protective, and risk factors on academic achievement-related outcomes of economically disadvantaged Latino youth. Journal of Community Psychology 31: 513-529. http://dx.doi.org/10.1002/jcop.10064.

Prezza, M. and M. Giuseppina. 2002. Perceived social support from significant others, family and friends and several socio-demographic characteristics. Journal of Community and Applied Social Psychology 12: 422-429. http://dx.doi.org/10.1002/casp.696.

Rahil Mahyuddin, Habibah Elias, Loh Sau Cheong, Muhd Fauzi Muhamad, Nooreen Noordin and Maria Chong Abdullah. 2006. The relationship between students' self-efficacy and their English language achievement. Asian Pacific Journal of Educators 21: 61-71.

Rahimi, A. and R. A. Bigdeli. 2014. Iranian EFL learners at loggerheads with perceived social support. Iranian Journal of Research in English Language Teaching 1: 31-37.

Rozumah Baharudin and Nor Sheereen Zulkefly. 2009. Relationships with father and mother, self-esteem and academic achievement amongst college students. American Journal of Scientific Research 6: 86-94.

Sabouripour, F. and S. B. Roslan. 2015. Self-efficacy, psychological well-being and resilience among international students. Paper presented at the 7 th International Conference on Education and New Learning Technologies, Barcelona, Spain. 68 July.

Sagone, E. and E. D. C. Caroli. 2013. Relationships between resilience, self-efficacy, and thinking styles in Italian middle adolescents. Procedia - Social and Behavioral Sciences 92: 838-845. http://dx.doi.org/10.1016/j.sbspro.2013.08.763.

Saim, N. J. 2013. Social support, coping, resilience, and mental health in Malaysian young unwed pregnant women and young mothers. PhD diss., Umea University, Sweden.

Sanders, P. and L. Sanders. 2009. Measuring academic behavioural confidence: The ABC Scale revisited. Studies in Higher Education 34(1): 19-35. http://dx.doi.org/10.1080/03075070802457058.

Schunk, D. H. 1991. Self-efficacy and academic motivation. Educational Psychologist 26(3): 207-231. http://dx.doi.org/10.1080/00461520.1991.9653133.

Schwarzer, R. and M. Jerusalem. 1995. Generalized self-efficacy scale. In Measures in health psychology: A user's portfolio. Causal and control beliefs, eds. J. Weinman, S. Wright and M. Johnston, 35-37. Windsor, UK: NFER-Nelson.

Serovich, J. M., J. A. Kimberly, K. E. Mosack and T. L. Lewis. 2001. The role of family and friend support in reducing emotional distress among HIV-positive women. AIDS Care 13: 335-341. http://dx.doi.org/10.1080/09540120120043982.

Shumaker, S. A. and A. Brownell. 1984. Toward a theory of social support: Closing conceptual gaps. Journal of Social Issues 40: 11-36. http://dx.doi.org/10.1111/j.1540-4560.1984.tb01105.x.

Solberg, V. S. and O. Villarreal. 1997. Examination of self-efficacy and assertiveness as mediators of student stress. Psychology: A Journal of Human Behaviour 34: 6169. 
Speight, N. P. 2009. The relationship between self-efficacy, resilience and academic achievement among African American urban adolescents. PhD diss., Howard University.

Stock, J. and M. W. Watson. 2003. Introduction to econometrics. New York: Prentice Hall.

Sun, J. and D. E. Stewart. 2007. Age and gender effects on resilience in children and adolescents. International Journal of Mental Health Promotion 9(4): 16-25. http://dx.doi.org/10.1080/14623730.2007.9721845.

Tabachnick, B. G. and L. S. Fidell. 2007. Using multivariate statistics. 5th ed. Boston: Pearson.

Tam, C. L. and Fatimah Yusooff. 2009. The effects of family functioning on self-esteem of children. European Journal of Social Sciences 9: 643-650.

Tasleem Hassim, C. Strydom and H. Strydom. 2013. Resilience in a group of Psychosocial Science students at the Northwest University (Portcheftroom campus). West East Journal of Social Sciences 2(1): 40-46.

Uchino, B. N. 2004. Social support and physical health: Understanding the health consequences of relationships. New Haven, CT: Yale University Press. http://dx.doi.org/10.12987/yale/9780300102185.001.0001.

Umberson, D. and J. K. Montez. 2013. Social relationships and health: A flashpoint for health policy. Journal of Health and Social Behaviour 51(1): 54-66.

UNICEF. 2005. More girls than boys stay in education to advanced level. http://www.unicef.org/malaysia/gift_6069.html (accessed 15 June 2014).

Urquhart, B. and J. A. Pooley. 2007. The transition experience of Australian students to university: The importance of social support. The Australian Community Psychologist 19(2): 78-91.

Wagnild, Y. and H. M. Young. 1993. Development and psychometric evaluation of the resilience scale. Journal of Nursing Measurement 1: 165-178.

Wagnild, G. 2009. The resilience scale user's guide for the US English version of the resilience scale and the 14-item resilience scale (RS-14). Worden, MT: The Resilience Centre.

Warner, R. M. 2012. Applied statistics: From bivariate to multivariate. 5th ed. Thousand Oaks, California: Sage Publications Inc.

Wasonga, T., D. E. Christman and L. Kilmer. 2003. Ethnicity, gender and age: Predicting resilience among high school urban students. American Secondary Education 32(1): 62-74.

Werner, E. E. and R. S. Smith. 1992. Overcoming the odds: High risk children from birth to adulthood. Ithaca, NY: Cornell University Press.

. 1989. Vulnerable but invincible: A longitudinal study of resilient children and youth. New York: Adams, Bannister, and Cox. 1982. Vulnerable, but invincible: A study of resilient children. New York: McGraw-Hill.

Wilks, S. E. and B. Croom. 2008. Perceived stress and resilience in Alzheimer's disease caregivers: Testing moderation and mediation models of social support. Aging \& Mental Health: An International Journal 12: 357-365. http://dx.doi.org/10.1080/13607860801933323. 
Wilks, S. E. 2008. Resilience amid academic stress: The moderating impact of social support among social work students. Advances in Social Work 9(2): 106125.

Wright, M. O. and A. S. Masten. 2005. Resilience processes in development: Fostering positive adaptation in the context of adversity. In Handbook of resilience in children, eds. S. Goldstein and R. B. Brooks, 17-37. New York: Springer. http://dx.doi.org/10.1007/0-306-48572-9_2.

$\mathrm{Xu}$, J. and L. Ou. 2014. Resilience and quality of life among Wenchuan earthquake survivors: The mediating role of social support. Public Health 128: 430-437. http://dx.doi.org/10.1016/j.puhe.2014.03.002.

Zaleski, E. H., C. Levey-Thors and K. M. Schiaffino. 1998. Coping mechanisms, stress, social support, and health problems in college students. Applied Developmental Science 2(3): 127-137. http://dx.doi.org/10.1207/s1532480xads0203_2.

Zimet, G. D., N. W. Dahlem, S. G. Zimet and G. K. Farley. 1988. The multidimensional scale of percieved social support. Journal of Personality Assessment 52: 30-41. http://dx.doi.org/10.1207/s15327752jpa5201_2. 